\title{
Structure control of silica-supported mono and bimetallic Au-Pt catalysts via mercapto capping synthesis
}

\author{
V. La Parola ${ }^{\mathrm{a}, *}$, M. Kantcheva ${ }^{\mathrm{b}}$, M. Milanova ${ }^{\mathrm{b}}$, A.M. Venezia ${ }^{\mathrm{a}, *}$ \\ a ISMN-CNR, Via Ugo La Malfa, 153 Palermo, Italy \\ ${ }^{\mathrm{b}}$ Department of Chemistry, Bilkent University, 06800 Bilkent, Ankara, Turkey
}

\section{A R T I C L E I N F O}

\section{Article history:}

Received 18 September 2012

Revised 4 November 2012

Accepted 7 November 2012

Available online 28 December 2012

\section{Keywords:}

$\mathrm{Au}$

$\mathrm{Pt}$

Au-Pt particles

MPTES stabilization

Thiophene HDS

XRD

XPS

FTIR

\begin{abstract}
A B S T R A C T
$\mathrm{SiO}_{2}$-supported monometallic and bimetallic platinum-gold catalysts are prepared by deposition of metal nanoparticles stabilized by mercaptopropyltriethoxysilane (MPTES) after different aging time of the solution containing metal ions and MPTES. The materials are tested in the hydrodesulfurization (HDS) reaction of thiophene and compared with corresponding catalysts prepared by the conventional deposition-precipitation (DP) method. The monometallic Pt and the bimetallic Au-Pt prepared by DP have comparable activity. With respect to the platinum catalyst prepared by DP, the corresponding platinum catalyst prepared by MPTES particle stabilization exhibits a substantial enhancement of the activity regardless the solution aging time. On the contrary, the MPTES-assisted Au-Pt catalysts have different activities, depending on the solution aging time, with the most active being the one obtained with the 5-day-aged solution. In accord with XRD, XPS, and FTIR, the aging time of the solution, through the different interaction of Pt or Au precursors with the mercapto groups, has a crucial effect on the structure and on the surface of the catalysts. The observed differences in the catalytic activity are related to the structural and compositional changes of the bimetallic particles.
\end{abstract}

(c) 2012 Elsevier Inc. All rights reserved.

\section{Introduction}

Supported noble metals have been used as HDS catalysts in alternative to the traditional CoMo systems [1-3]. Due to their elevated hydrogenation activity, the Pd- and Pt-based catalysts are particularly suitable for deep HDS involving hydrogenation of the aromatic hydrocarbon as a preliminary step to the C-S cleavage [4]. At variance with the traditional CoMo or NiMo catalysts which are active as sulfides, Pd and Pt catalysts are active in the metallic state, and they allow to work at milder conditions in terms of temperature and pressure. Nevertheless, a major drawback in their use is their limited lifetime due to the easy poisoning of the active sites by sulfur [5-7]. Appropriate choice of the support and/or alloying with another metal is possible ways for increasing the sulfur tolerance [8-10]. Bimetallic systems such as Au-Pd, Au-Pt, and Pd-Pt catalysts, used in hydrodesulfurization and hydrogenation reactions, exhibit enhanced activity and longer lifetime as compared to the monometallic palladium and platinum catalysts [11-13]. Bulky metallic gold has limited ability to dissociate $\mathrm{H}_{2}$ molecules [14]; however, as supported nanostructured particles, it has been used successfully in different hydrogenation reactions, such as hydrogenation of nitroaromatic compounds or hydrodesulfuriza-

\footnotetext{
* Corresponding authors. Fax: +39 0916809399.

E-mail addresses: laparola@pa.ismn.cnr.it (V. La Parola), venezia@pa.ismn.cnr.it (A.M. Venezia).
}

tion of benzothiophene [15-17]. In the case of the hydrodesulfurization of dibenzothiophene, gold particles supported over silica are able to activate the $\mathrm{C}-\mathrm{S}$ bond rupture allowing, under high hydrogen pressure, the direct sulfur extrusion pathway of the HDS reaction [16]. Most of the reported studies confirm that gold acts as a structural and/or as an electronic promoter of the Pd or Pt noble metals providing synergistic catalytic effect $[12,17,18]$. Moreover, inhibition of coke formation and enhancement of the hydrogenation activity with $\mathrm{Au}-\mathrm{Pt}$ and $\mathrm{Au}-\mathrm{Pd}$ systems have been reported and attributed to the geometric effect resulting from the dilution of the Pd or Pt ensemble in the binary Au-Pd and Au-Pt systems $[12,18]$. The extent of the alloy formation and its composition is strongly dependent on the supports and also on the preparation method [12]. To this respect, we have recently shown how differences in the metal-carrier interaction, induced by support functionalization with mercapto groups, affected the Au-Pd dispersion, the formation and the composition of alloyed phases and therefore the HDS activity [19]. Unlike the Au-Pd system which in the macroscopic state form a continuous range of solid solutions and allows the attainment of truly bimetallic nanoparticles, the Au-Pt-phase diagram exhibits a considerable miscibility gap (i.e., between 18 and $97 \mathrm{wt} \%$ ) [20]. Phase segregation of the two metals and inhomogeneous composition of the resulting bimetallic Au-Pt particles are quite common. However, sufficiently small particles, obtained through a variety of chemical methods, can form true solid solution [21]. As for Au-Pd systems described 
before [19], the possibility of modifying the structure of supported $\mathrm{Au}-\mathrm{Pt}$ particles by the use of mercapto groups is here exploited.

To this aim, a new procedure for the preparation of silica-supported monometallic and bimetallic Au-Pt catalysts is described. $\mathrm{Au}, \mathrm{Pt}$, and $\mathrm{Au}-\mathrm{Pt}$ particles are first synthesized by using mercaptopropyltriethoxysilane (MPTES) as stabilizing agent and as carrier for the particle deposition over amorphous silica. In order to discriminate the effect of the ligand-metal interaction, different aging time of the metal-MPTES solution before adding silica is considered. The obtained solids are characterized by X-ray diffraction (XRD), X-ray photoelectron spectroscopy (XPS), and Fourier transform infrared spectroscopy (FTIR) techniques, and they are preliminary tested in the thiophene hydrodesulfurization (HDS) reaction.

\section{Experimental}

\subsection{Sample preparation}

Catalysts were prepared by dissolving metallic precursors $\left(\mathrm{AuCl}_{3}\right.$ or $\left.\mathrm{PtCl}_{2}\right)$ in $5 \mathrm{~mL}$ of ethanol and adding equimolar amounts of MPTES with respect to the metal precursors. It is worth to mention that the gold precursor dissolved immediately in ethanol and upon addition of the MPTES reagent the solution started darkening until becoming completely black in $4 \mathrm{~h}$. The platinum precursor, which was not soluble in ethanol, dissolved in the presence of MPTES giving a clear yellow solution. Adding MPTES to the suspension containing the gold and the platinum precursors produced a yellowish clear solution. The obtained mixture was left aging for 0,1 , or 5 days; thereafter, commercial $\mathrm{SiO}_{2}$ (Aldrich; surface area of $546 \mathrm{~m}^{2} / \mathrm{g}$ ) was added and left $24 \mathrm{~h}$ under stirring at room temperature. The samples were then filtered, washed with ethanol, dried at $80^{\circ} \mathrm{C}$ for $3 \mathrm{~h}$, and calcined at $400{ }^{\circ} \mathrm{C}$ for $1 \mathrm{~h}$. The metal loading, checked by X-ray fluorescence, was equal to the nominal $1 \mathrm{wt} \%$ for each metal. The silica-supported samples were labeled with the element symbols, Au, Pt, or AuPt followed by the numbers $0,1,5$ referring to the aging time of 0 day, 1 day, and 5 days, respectively, of the metal-MPTES solution before contacting it with the silica carrier. For comparison reason, a monometallic platinum catalyst and a bimetallic AuPt catalyst, with the same metal loadings of the above ones, were prepared by deposition-precipitation method using urea as precipitating agent [11].

\subsection{Samples characterization}

X-ray diffraction (XRD) analyses were performed with a Bruker goniometer using $\mathrm{Ni}$-filtered $\mathrm{Cu} \mathrm{K} \alpha$ radiation. A proportional counter and $0.05^{\circ}$ step sizes in $2 \theta$ were used. The assignment of the crystalline phases was based on the JPDS powder diffraction file cards [22].

The X-ray photoelectron spectroscopy (XPS) analyses were carried out with a VGMicrotech ESCA 3000Multilab, equipped with a dual $\mathrm{Mg} / \mathrm{Al}$ anode. The unmonochromatized $\mathrm{Al} \mathrm{K} \alpha$ source $(1486.6 \mathrm{eV})$ run at $14 \mathrm{kV}$ and $15 \mathrm{~mA}$ was used to excite the spectra. The analyzer operated in the constant analyzer energy (CAE) mode. For the individual peak energy regions, a pass energy of $20 \mathrm{eV}$ set across the hemispheres was used. Survey spectra were measured at $50 \mathrm{eV}$ pass energy. The samples were analyzed as powders mounted on a double-sided adhesive tape. The pressure in the analysis chamber was in the range of $10^{-8}$ Torr during data collection. The constant charging of the samples was removed by referencing all the energies to the $\mathrm{C} 1 \mathrm{~s}$ set at $285.1 \mathrm{eV}$, arising from the adventitious carbon. The invariance of the peak shapes and widths at the beginning and at the end of the analyses ensured absence of differential charging. Analyses of the peaks were performed with the software provided by VG, based on non-linear least squares fit- ting program using a weighted sum of Lorentzian and Gaussian component curves after background subtraction according to Shirley and Sherwood $[23,24]$. Atomic concentrations were calculated from peak intensity using the sensitivity factors provided with the software. The binding energy values are quoted with a precision of $\pm 0.15 \mathrm{eV}$ and the atomic percentage with a precision of $\pm 10 \%$.

The FT-IR spectra were recorded using a Bomem Hartman \& Braun MB-102 model FT-IR spectrometer with a liquid nitrogencooled MCT detector at a resolution of $4 \mathrm{~cm}^{1}$ (100 scans). The self-supporting disks $\left(\sim 0.01 \mathrm{~g} / \mathrm{cm}^{2}\right)$ were activated in the IR cell by heating for $1 \mathrm{~h}$ in a vacuum at $350{ }^{\circ} \mathrm{C}$ and in 100 Torr of oxygen at the same temperature, followed by evacuation for $1 \mathrm{~h}$ at $350^{\circ} \mathrm{C}$. The adsorption of $\mathrm{CO}$ was carried out at room temperature and $\mathrm{CO}$ equilibrium pressure of 50 Torr. The stability of the adsorbed species was monitored by evacuation of gaseous $\mathrm{CO}$ at room temperature for $30 \mathrm{~min}$ to a residual pressure of $5 \times 10^{-4}$ Torr. The spectra of adsorbed gases were obtained by subtracting the spectra of the activated sample from the recorded spectra. The sample spectra were also gas-phase corrected.

\subsection{HDS reaction}

The hydrodesulfurization of thiophene was carried out in the vapor phase using a continuous flow microreactor [12]. An amount of $200 \mathrm{mg}$ of catalyst (sieved fraction $210-430 \mathrm{~mm}$ ), diluted with inert particles of $\mathrm{SiC}$ (in a weight ratio of $5: 1$ with respect to the catalyst), was used for each test. The samples were reduced in situ for $2 \mathrm{~h}$ in $\mathrm{H}_{2}$ (flow at $50 \mathrm{ml} \mathrm{min}{ }^{-1}$ and at $400{ }^{\circ} \mathrm{C}$ at a rate of $7{ }^{\circ} \mathrm{C} \mathrm{min}^{-1}$ ). After purging with nitrogen, the HDS of thiophene was carried out at $340{ }^{\circ} \mathrm{C}$ with 5.3 vol.\% thiophene in $\mathrm{H}_{2}$ and WHSV $=7500 \mathrm{~h}^{-1}$. The reaction products were analyzed by online gas chromatography (Carlo Erba GC 8340 gaschromatograph). Fractional conversions were calculated from the ratio of the peak area of the $C_{4}$ products over the sum of the peak areas of the products and thiophene. The reaction rate constants for HDS ( $\left.k_{\mathrm{HDS}}\right)$ per gram of catalyst of the pseudo first-order reaction with respect to thiophene (hydrogen in large excess) were calculated using the integral reactor equation

$k_{\mathrm{HDS}}=-\ln (1-x) F_{0} / W$

where $x$ is the fractional conversion at the steady-state conditions, reached after $10 \mathrm{~h}$ on stream, assuming $F_{0}\left(\mathrm{ml} \mathrm{s}^{-1}\right)$ the volumetric reagent gas flow and $W$ the weight of the catalysts $(\mathrm{g})$. A percentage of initial deactivation \% $d$ was calculated by the differences between the conversion at the beginning of the test $x_{i}$, considered after 2 min of time on stream, and conversion at the steady-state plateau $x_{f}$ as

$\% d=100\left(x_{i}-x_{f}\right) / x_{i}$

[11]. Measurements of the rate constants at four different temperatures $\left(340{ }^{\circ} \mathrm{C}, 355^{\circ} \mathrm{C}, 370^{\circ} \mathrm{C}\right.$, and $395^{\circ} \mathrm{C}$ ) for selected samples allowed the determination of the activation energy.

\section{Results}

\subsection{Catalytic activity}

Thiophene HDS conversion data were collected at 8 min interval during the first $2 \mathrm{~h}$ and then at 60-min interval over a period of $16 \mathrm{~h}$. A typical plot of the rate constant versus time on stream is shown in Fig. 1 for the AuPt5 sample, with the corresponding Arrhenius plot given in the inset. For all samples, a plateau of steady-state conditions was reached after about $10 \mathrm{~h}$. The activation energies calculated for all the samples were of the order of $45 \mathrm{~kJ} \mathrm{~mol}^{-1}$, close to the values obtained for supported AuPd 


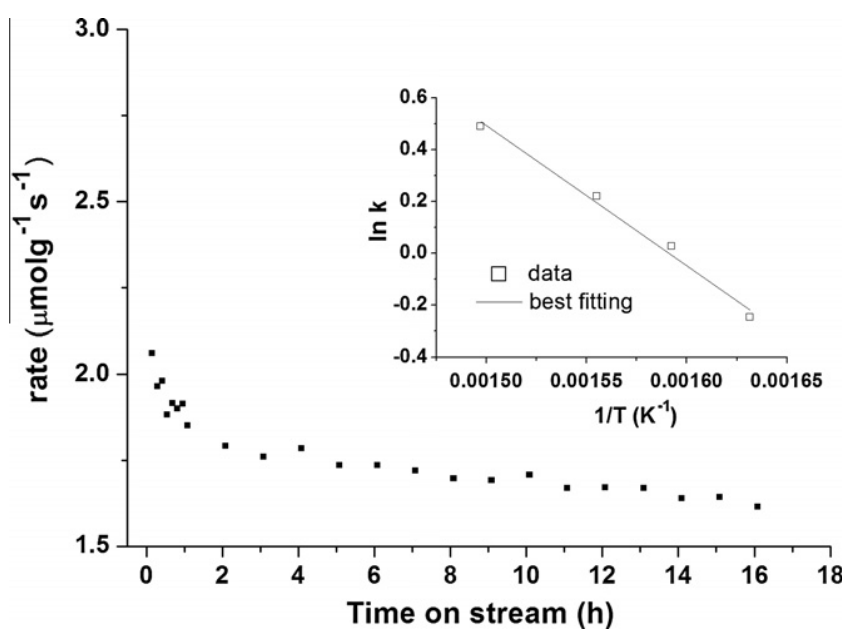

Fig. 1. AuPt5 HDS reaction rate versus time on stream. The Arrhenius plot is given in the inset.

catalysts [11]. In Fig. 2, the thiophene HDS reaction rate of the samples as a function of different aging time of the metal-MPTS solution before adding the support is shown. The activity of the monometallic gold catalysts, not reported in the diagram, was negligible in accord with a previous study [11]. As compared to the deposition-precipitation method, the new synthesis with the use of the MPTES ligand produces considerably more active monometallic platinum catalysts, regardless the aging time of the solution. For the bimetallic catalysts, with respect to the DP sample, a large increase in the catalytic activity, almost comparable with that of the MPTES-assisted monometallic platinum, is observed for the AuPt5 sample obtained from the 5-day-aged MPTES solution. Interestingly, there is no evidence of synergy between the two metals, contrary to earlier results showing distinct synergy between gold and platinum in the reaction of naphthalene hydrogenation [12]. In any case, the catalysts prepared with the MPTES method are more active than those prepared by the classical depositionprecipitation method. The deactivation percentages, indicative of a certain catalyst instability, follow the same trend of the reaction rate. Indeed, the deactivation percentage of $20 \%$ is observed for both Pt catalysts, Pt 0 and Pt5, whereas a large difference in the deactivation percentages is observed for the bimetallic catalysts, with $55 \%$ for the AuPt0 and $13 \%$ for the AuPt5.

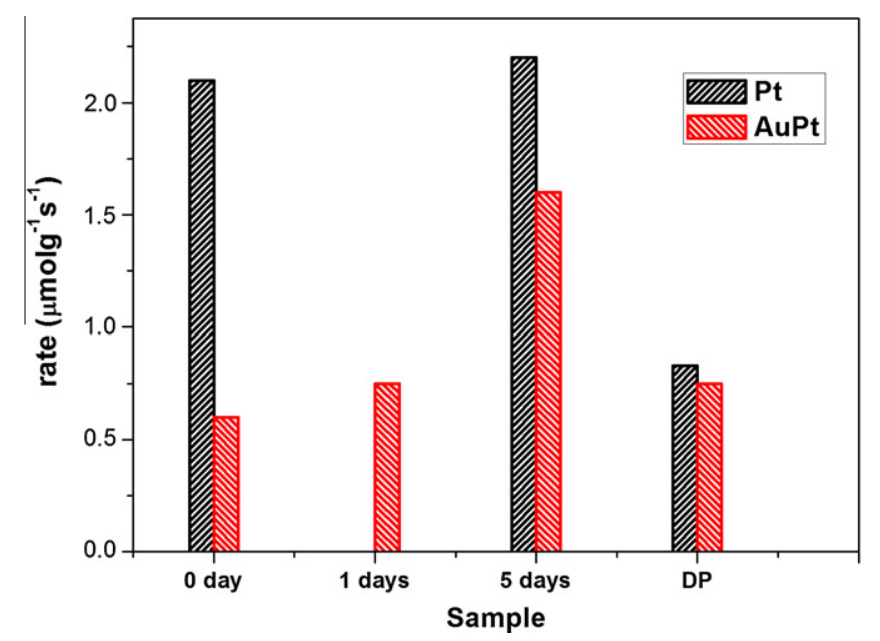

Fig. 2. Thiophene HDS rate of calcined samples as a function of different aging time of the metal-MPTS solution before adding the support. DP refers to the sample prepared from classical deposition-precipitation method.

\subsection{Structural characterization}

In order to correlate the activity with the structural properties, the modification of the catalysts, both as dried (at $80^{\circ} \mathrm{C}$ for $3 \mathrm{~h}$ ) and as calcined (at $400{ }^{\circ} \mathrm{C}$ for $1 \mathrm{~h}$ ), with increasing the aging time of the metal-MPTES solution, was investigated by XRD, XPS, and FTIR techniques. In Table 1, the structural phases and the sizes of the crystalline particles as obtained from the Scherrer analysis of the diffraction peaks are summarized for the monometallic and bimetallic samples after being calcined. All the catalysts in the dry state, according to the XRD analysis, are amorphous. On the contrary, as shown in Figs. 3-5, the calcined samples are crystalline.

As shown in Fig. 3, the gold samples, Au0 and Au5, calcined at $400{ }^{\circ} \mathrm{C}$ and, respectively, obtained with the just prepared solution and from the 5-day-aged solution exhibit XRD patterns characteristic of metallic gold. The diffractogram of Au0 sample contains two sharp peaks at $2 \theta$ of $38.2^{\circ}$ and $44.3^{\circ}$ due to metallic Au (111) and $\mathrm{Au}$ (200) reflections, respectively. Through the Scherrer analysis of these peaks, an average gold particles size of $39 \mathrm{~nm}$ is obtained. The diffractogram of the Au5 sample contains two peaks in correspondence of the two metal gold reflections. Through the curve fitting procedure, each reflection is decomposed into two component peaks of different width. The narrow peak is due to big particles of $36 \mathrm{~nm}$, the wide peak is due to gold particles with smaller size around $4 \mathrm{~nm}$. As obtained from the peak intensity analyses and as reported in Table 1, the small particles are present in larger amount.

Table 1

Silica-supported calcined metal catalysts with the corresponding metal phases and metal particle diameters.

\begin{tabular}{lll}
\hline Sample & Phases & Particle diameter $(\mathrm{nm})^{\mathrm{a}}$ \\
\hline Au0 & Metallic Au & 39 \\
Au5 & Metallic Au & $4(82 \%) 36(18 \%)$ \\
Pt0 & Amorphous & - \\
Pt5 & Amorphous & - \\
AuPt0 & Au65Pt35 & $3(63 \%)$ \\
& Metallic Pt & $13(37 \%)$ \\
AuPt1 & Metallic Au & $7(54 \%)$ \\
& Metallic Pt & $5(45 \%)$ \\
AuPt5 & Metallic Au & $30(29 \%)$ \\
& Au52Pt48 & $3(71 \%)$ \\
AuPt(DP) & Metallic Au & $15(56 \%)$ \\
& Au15Pt85 & $8(44 \%)$ \\
\hline
\end{tabular}

a The percentages of the Sherrer used peak intensities are given in parentheses.

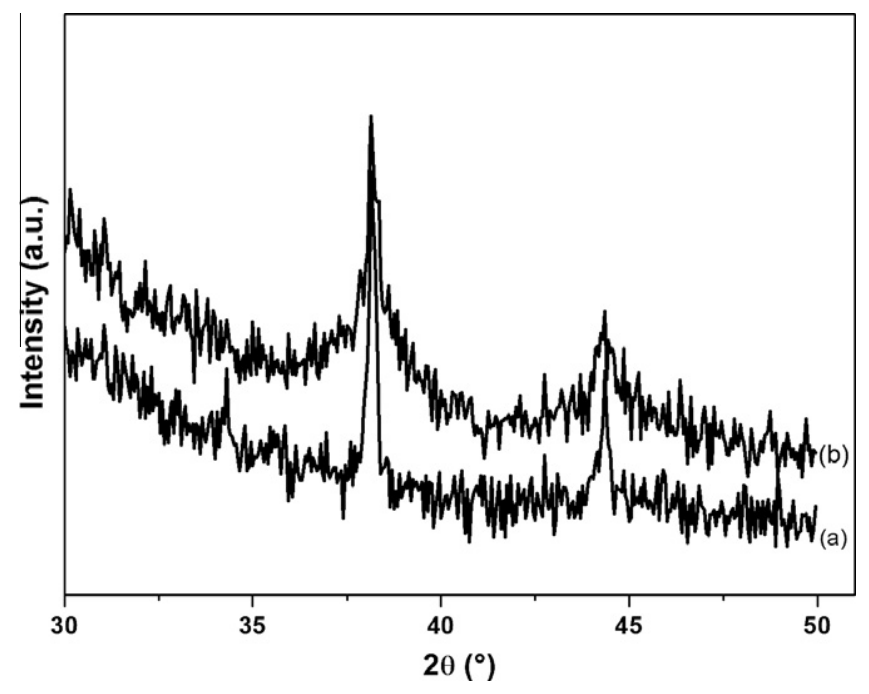

Fig. 3. X ray diffraction of (a) Au0 and (b) Au5. 


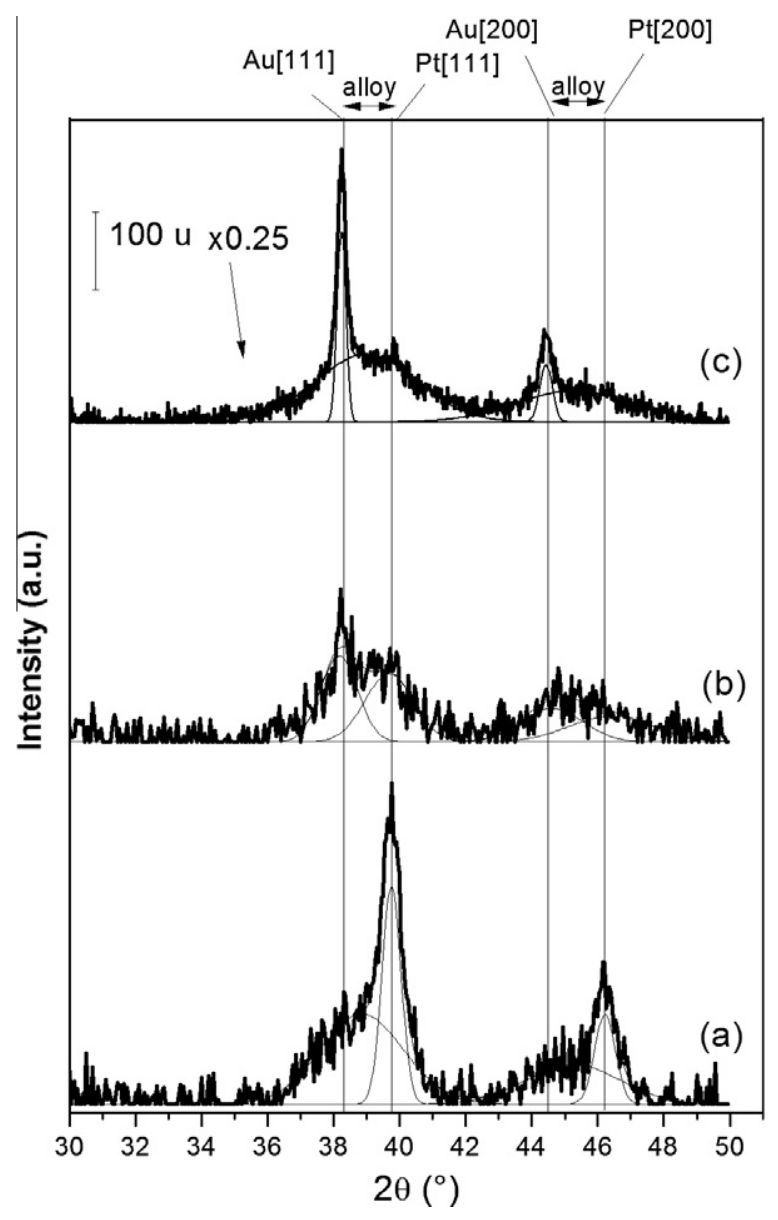

Fig. 4. X ray diffraction of (a) AuPt0, (b) AuPt1 and (c) AuPt5.

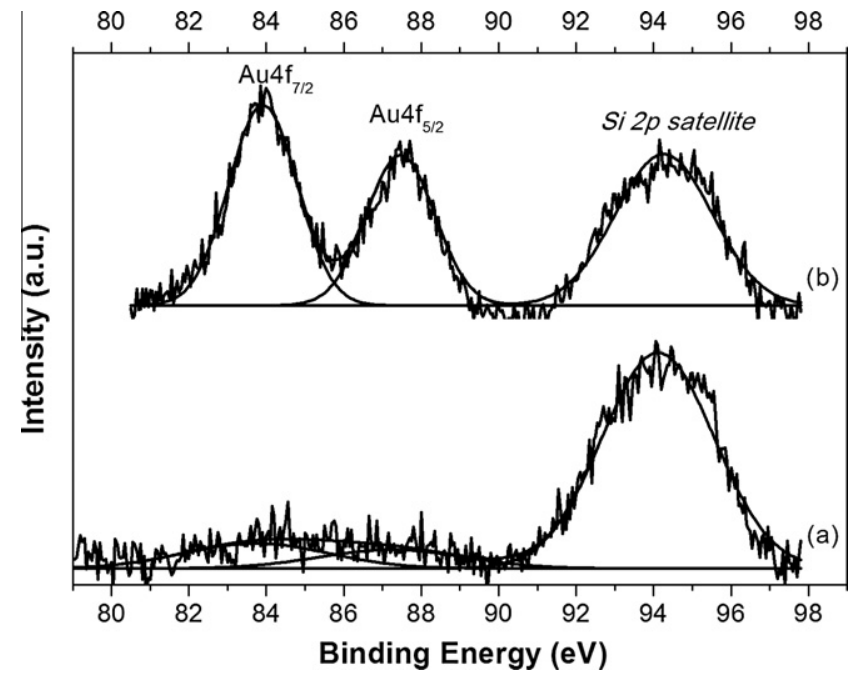

Fig. 5. XPS Au $4 \mathrm{f}$ region of (a) Au0 and (b) Au5.

The diffractograms of the dried and calcined monometallic platinum samples, regardless the solution aging time, did not contain any peak, suggesting the presence of amorphous structure or very small platinum particles undetectable by the technique. On the contrary, the XRD pattern of the monometallic Pt catalyst prepared by DP (not shown for brevity) exhibited distinct reflection peaks at $2 \theta$ of $39.8^{\circ}$ and $46.3^{\circ}$ typical of metallic platinum, with particle sizes of about $9 \mathrm{~nm}$.
According to the XRD patterns of the bimetallic Au-Pt samples, shown in Fig. 4, the catalyst structure undergoes significant changes when increasing the aging time of the metal-MPTES solution from the instant zero to the period of 5 days before adding the silica support. Curve fitting of the peaks lying in the $2 \theta$ ranges between $36^{\circ}$ and $42^{\circ}$ and between $43^{\circ}$ and $48^{\circ}$, typically of Au (111) and Pt (111) and $\mathrm{Au}(200)$ and Pt (200) reflections, respectively, allows to define two components for each range. One of the components is due to metallic Pt or Au, whereas the other component shifted with respect to the pure metal positions is attributed to $\mathrm{Au}_{x} \mathrm{Pt}_{y}$ alloy. The evaluation of the lattice parameter from the position of the peaks provides, through the application of Vegard's law [25], the solid solution composition. The derived phases and their relative percentages along with the corresponding particles sizes are listed in Table 1. At time zero, large platinum particles of $13 \mathrm{~nm}$ are formed along with smaller ( $3 \mathrm{~nm}$ ) gold enriched alloyed particles with average composition $\mathrm{Au}_{65} \mathrm{Pt}_{35}$. By letting the solution rest for 1 day before introducing silica, we observe the segregation of pure gold and pure platinum with average particle sizes of $7 \mathrm{~nm}$ and $5 \mathrm{~nm}$, respectively. The extension of the solution aging time causes the prevalent formation (71\%) of $\mathrm{Au}_{52} \mathrm{Pt}_{48}$ alloy particles of small dimension ( $3 \mathrm{~nm}$ ) along with a minority (3\%) of pure gold particles of big dimension $(30 \mathrm{~nm})$. It should be pointed out that the XRD technique does not allow to discriminate the situation of separate particles from core-shell structures; in other words, the present XRD data can be also attributed to particles formed by large core of $\mathrm{Pt}(\mathrm{Au})$ surrounded by thinner layer of alloyed phases or vice versa. The XRD pattern of the bimetallic catalyst prepared by DP was similar to that of the AuPt5 catalyst, with bigger gold particles and smaller alloy particles. However, as shown in Table 1, the alloy particles present in the AuPt(DP) were bigger and with a more platinum enriched composition as compared to the AuPt5 catalyst.

The selected samples, AuPt0 and AuPt5, are also analyzed by XRD after the catalytic test. Although the poor quality of the spectra, not shown in here, did not allow a proper curve fitting, some qualitative information could still be obtained. Indeed, with respect to the fresh sample, no appreciable difference was observed for the AuPt5 pattern, which was still characterized by a sharper gold peak and by a broad alloy feature. On the contrary, the pattern of the AuPt0 exhibited a broad peak in correspondence of the $\mathrm{Au}$ (111) position, and quite interestingly, it did not contain any platinum-related peak previously observed in the fresh sample, suggesting a profound bulk structural modification of the platinum and the absence of sintering during reaction.

X-ray photoelectron spectroscopy was used to determine the particle composition. In Table 2, the gold and platinum main binding energies and the metal to silicon XPS-derived atomic ratios along with the $\mathrm{S} / \mathrm{Si}$ atomic ratios are summarized. Typical Au $4 \mathrm{f}$ spectra are shown in Fig. 5 for the monometallic gold sample in the calcined state. The spectral region contains also a broad peak at $\sim 94 \mathrm{eV}$ due to the $\mathrm{Si} 2 \mathrm{p}$ satellite, purposely included for a direct intensity comparison [19]. The $\mathrm{Au} 4 \mathrm{f}_{7 / 2}$ position in all the spectra of the dried catalysts is at $84.1 \pm 0.2 \mathrm{eV}$ typical of metallic gold [11] and quite below the value reported for $\mathrm{Au}$-thiol bonding (at $\mathrm{ca}$. $85 \mathrm{eV}$ ) [26]. Small differences, observed in the calcined samples, are not significant, being most of them, except for the zero time aged sample, within the experimental error. No sulfur-related peaks were present in the monometallic gold samples. The surface $\mathrm{Au} / \mathrm{Si}$ atomic ratio of the monometallic sample, in both the dried and the calcined state, increases with the MPTES solution aging time and is in accord with the differences in particle sizes derived from XRD and listed in Table 1. Indeed, the ratio reflects the better gold dispersion of the monometallic obtained with the 5-day-aged solution. Opposite behavior is observed for the bimetallic samples 
Table 2

Gold $\left(\mathrm{Au} 4 \mathrm{f}_{7 / 2}\right.$ ) and platinum ( $\mathrm{Pt} 4 \mathrm{f}_{7 / 2}$ ) XP binding energies and XPS-derived atomic ratio of gold and platinum with respect to silicon.

\begin{tabular}{|c|c|c|c|c|c|c|c|c|c|c|}
\hline \multirow[t]{2}{*}{ Sample } & \multicolumn{2}{|c|}{$\mathrm{Au} 4 \mathrm{f}_{7 / 2}(\mathrm{eV})$} & \multicolumn{2}{|c|}{$\mathrm{Au} / \mathrm{Si}(0.003)^{\mathrm{a}}$} & \multicolumn{2}{|c|}{ Pt $4 f_{7 / 2}(e V)$} & \multicolumn{2}{|c|}{$\mathrm{Pt} / \mathrm{Si}(0.003)^{\mathrm{a}}$} & \multirow{2}{*}{$\begin{array}{l}\mathrm{S} / \mathrm{Si}^{\mathrm{b}} \\
\text { Dried }\end{array}$} & \multirow{2}{*}{$\begin{array}{l}\mathrm{Au} / \mathrm{Pt} \\
400^{\circ} \mathrm{C}\end{array}$} \\
\hline & Dried & $400{ }^{\circ} \mathrm{C}$ & Dried & $400{ }^{\circ} \mathrm{C}$ & Dried & $400^{\circ} \mathrm{C}$ & Dried & $400^{\circ} \mathrm{C}$ & & \\
\hline Au0 & 84.1 & 83.7 & 0.001 & 0.001 & & & & & & \\
\hline Au5 & 84.0 & 83.9 & 0.008 & 0.007 & & & & & & \\
\hline Pt0 & & & & & 71.9 & $\begin{array}{l}72.2(73 \%) \\
74.0(23 \%)\end{array}$ & 0.014 & 0.016 & 0.019 & \\
\hline Pt5 & & & & & 71.8 & $72.3100 \%)$ & 0.005 & 0.006 & 0.012 & \\
\hline \multirow[t]{2}{*}{ AuPt0 } & 84.3 & 84.1 & 0.009 & 0.007 & 72.0 & $\begin{array}{c}71.5(72 \%) \\
73.9(28 \%)\end{array}$ & 0.002 & 0.004 & 0.011 & 1.7 \\
\hline & & $83.9^{c}$ & & $0.002^{c}$ & & $71.7^{\mathrm{c}}$ & & $0.002^{\mathrm{c}}$ & & $1.0^{\mathrm{c}}$ \\
\hline AuPt1 & 84.1 & 84.0 & 0.006 & 0.005 & 71.8 & $\begin{array}{l}71.6(71 \%) \\
73.7(29 \%)\end{array}$ & 0.005 & 0.006 & 0.014 & 0.9 \\
\hline \multirow[t]{2}{*}{ AuPt5 } & 83.9 & 83.9 & 0.004 & 0.004 & 71.8 & $\begin{array}{c}71.5(81 \%) \\
73.9(19 \%)\end{array}$ & 0.009 & 0.010 & 0.015 & 0.4 \\
\hline & & $83.8^{\mathrm{c}}$ & & $0.002^{c}$ & & $71.4^{\mathrm{c}}$ & & $0.006^{\mathrm{c}}$ & & $0.3^{c}$ \\
\hline AuPt(DP) & & 84.1 & & 0.013 & & $\begin{array}{l}71.2(63 \%) \\
73.6(37 \%)\end{array}$ & & 0.007 & & 1.4 \\
\hline
\end{tabular}

\footnotetext{
a In parenthesis, the theoretical ratio is given.

b The sulfur peak disappears completely in the calcined samples.

c The values refer to the aged sample.
}

where the $\mathrm{Au} / \mathrm{Si}$ atomic ratio, in both dried and calcined samples, decreases with the solution aging time.

The $\mathrm{Pt} 4 \mathrm{f}_{7 / 2}$-binding energies and the $\mathrm{Pt} / \mathrm{Si}$ atomic ratios of the monometallic platinum samples are given also in Table 2 . The dried samples are characterized by one component at $71.9 \pm 0.1 \mathrm{eV}$, a higher value as compared to the binding energy reported in literature for metallic $\operatorname{Pt}(0)$ and quite lower than the binding energy of PtO [12]. In the $S 2 p$ region, not shown for simplicity, a peak at $161.8 \mathrm{eV}$ negatively shifted with respect to a mercaptopropyl groups bounded to silica was present [27]. The positive shift of $\mathrm{Pt} 4 \mathrm{f}$ with respect to metallic Pt and the negative shift of S 2p with respect to the mercapto group are due to a charge transfer from Pt nanoparticles to sulfur, indicative of a Pt-S chemical interaction [28]. Upon calcination, the sulfur peak disappears because of the decomposition and removal of the mercaptopropyl groups. At the same time, the main $\mathrm{Pt} 4 \mathrm{f}_{7 / 2}$ peak shifts to high energy typical of oxidized platinum. In Fig. 6 , the Pt $4 \mathrm{f}$ spectra of the calcined monometallic platinum samples after zero and 5 days of aging are displayed. As listed in Table 2 and also shown in Fig. 6a, the curve fitting routine allowed to simulate the spectrum of the calcined sample Pt0 with two Pt $4 \mathrm{f}$ components, one at



Fig. 6. XPS Pt $4 \mathrm{f}$ region of (a) Pt0 and (b) Pt5.
$72.2 \mathrm{eV}$ due to PtO and the other at $74.0 \mathrm{eV}$ due to $\mathrm{PtO}_{2}[29,30]$. The spectrum of the Pt5 was fitted with only the PtO component, however, given the broadness of the peak the presence of the other oxide component may not be completely ruled out. As indicated by the Pt/Si atomic ratios in Table 2, opposite to the trend observed for the gold catalysts, the platinum surface atomic concentration, in both the dried and the calcined samples, decreases with the aging time of the solution. It is worth noting that the S/Si atomic ratio of the dried samples follows the same trend as the Pt/Si ratio. The $\mathrm{S}$ $2 \mathrm{p}$ peak was absent in the calcined samples.

Concerning the bimetallic catalysts, as shown in Table 2, the corresponding Au $4 \mathrm{f}_{7 / 2}$-binding energies of the dried samples are typical of metallic gold, while the $\mathrm{Pt} 4 \mathrm{f}_{7 / 2}$ are again typical of platinum bound to sulfur. The $\mathrm{S} / \mathrm{Si}$ atomic ratios are almost the same in the three samples after the different aging time, while the metal/Si atomic ratios change noticeably, with the $\mathrm{Au} / \mathrm{Si}$ decreasing and the $\mathrm{Pt} / \mathrm{Si}$ increasing with the solution aging time. The binding energy region including both $\mathrm{Pt} 4 \mathrm{f}$ and Au $4 \mathrm{f}$ spectra is displayed for the calcined bimetallic samples in Fig. 7. Again, the $\mathrm{Au} 4 \mathrm{f}_{7 / 2}$ position is typical of metallic gold. The platinum spectra are fitted in all samples with two contributions: a low energy doublet with $\mathrm{Pt}$ $4 \mathrm{f}_{7 / 2}$ at $71.5 \mathrm{eV}$, attributed to metallic platinum and a high energy contribution at $73.8 \mathrm{eV}$ attributed to $\mathrm{PtO}_{2}$. The low-binding energy component corresponding to more than $70 \%$ of the total amount of platinum, not detected in the calcined monometallic Pt samples, is attributed to metallic platinum in close contact with gold. The binding energy is similar to the values reported by Li et al. [31] and by Xu et al. [32] for the core-shell structure of AuPt particles supported on carbon. The values here reported for both the Au $4 \mathrm{f}$ and the Pt $4 \mathrm{f}$ are about $1 \mathrm{eV}$ lower as those recently reported by Doherty et al. [33] for PtAu alloy particles. The difference may be due to the use of different charging compensation procedure. It is worth to notice from the Au/Pt atomic ratio, given in Table 2 for the calcined samples, the progressive platinum surface enrichment with the increase of the aging time. For comparison reason in Table 2, the XPS data of the AuPt(DP) sample are given. The results are similar to those of the MPTES-assisted bimetallic samples except for the larger gold surface concentration.

XPS analyses of the used AuPt0 and AuPt5 samples were performed, and the results are summarized in Table 2 . The only significant difference between the XPS results on the fresh and aged catalysts is the large decrease in the $\mathrm{Au} / \mathrm{Pt}$ atomic ratio observed in the AuPt0 sample. 


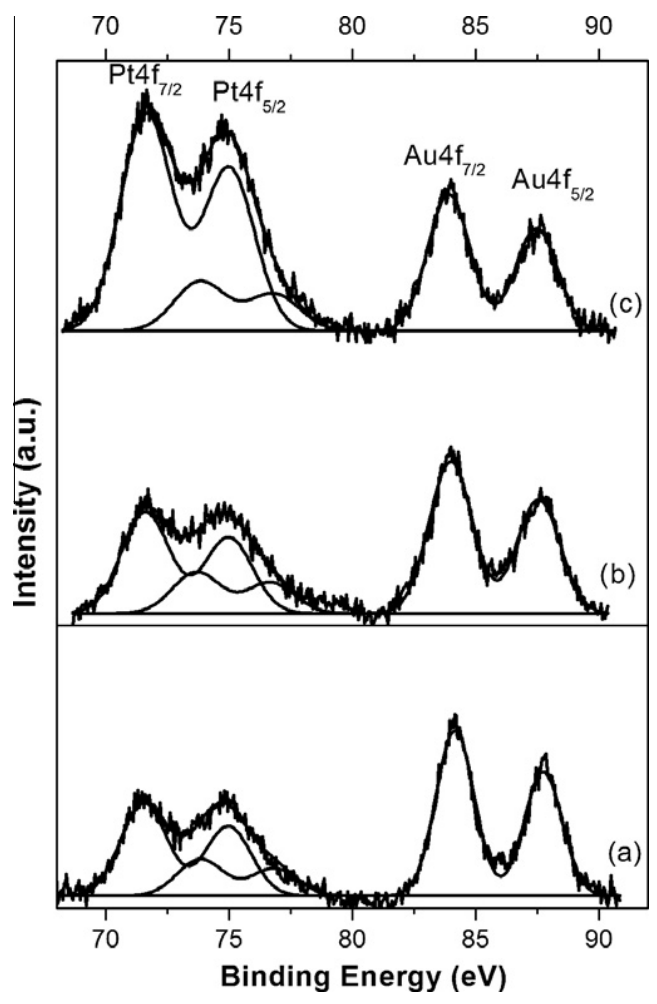

Fig. 7. XPS Pt $4 \mathrm{f}$ and $\mathrm{Au} 4 \mathrm{f}$ region of (a) AuPt0, (b) AuPt1 and (c) AuPt5.

More detailed information on the structural properties of the calcined samples is obtained by FTIR spectroscopy. In Fig. 8, the FT-IR spectra of the monometallic Au-containing catalysts detected in the presence of 50 Torr of $\mathrm{CO}$ (thick line) and after the evacuation for $30 \mathrm{~min}$ at room temperature (thin line) are displayed. In Fig. 8a and b, the spectra of the calcined gold catalysts prepared with the 0-day-aged- and the 5-day-aged-solutions are shown, respectively. The two spectra exhibit both two bands at 2026 and $2002 \mathrm{~cm}^{-1}$, whereas the spectrum of Fig. 8b, referring to the sample Au5, exhibits an additional high-frequency peak at $2117 \mathrm{~cm}^{-1}$. Such peak is generally attributed to $\mathrm{CO}$ coordinated on neutral Au nanoparticles [34-37]. On the contrary, the assignment of the lowfrequency bands is quite controversial. Low-frequency shift of the $\mathrm{CO}$ stretching bands has been attributed to the negatively charged

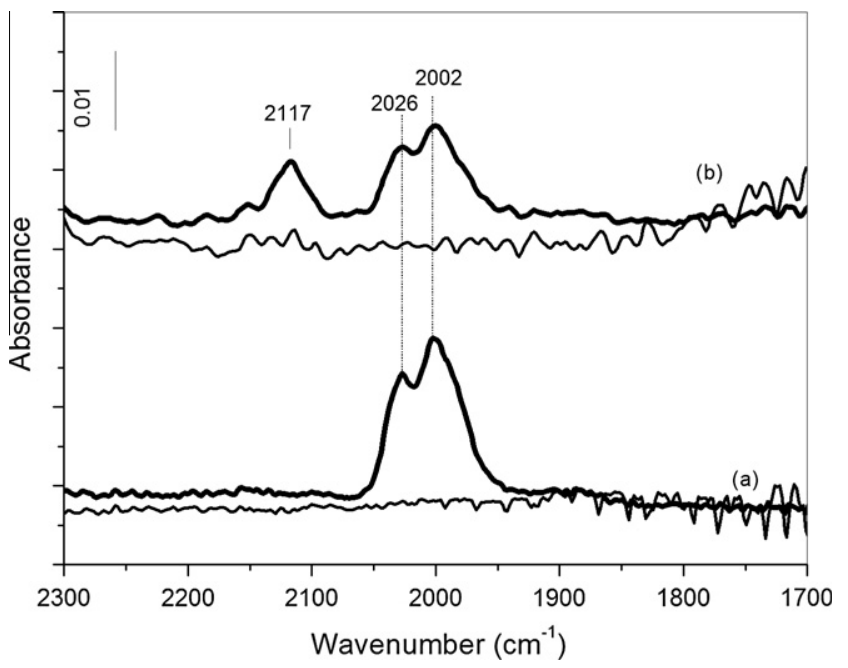

Fig. 8. FTIR spectra of $\mathrm{CO}$ (50 Torr) adsorbed at room temperature (thick line) and after evacuation of $\mathrm{CO}$ for $30 \mathrm{~min}$ at room temperature (thin line) on (a) Au0 and (b) Au5. gold particles supported over reducible oxides [38-40]. Some authors attributed these low-frequency bands to bridged $\mathrm{CO}$ adsorbed on big gold particles $[41,42]$. In the present case, considered the inert nature of the silica support, it is reasonable to attribute the low-frequency bands to bridge-bonded CO. In accord with XRD and XPS data, the Au5 contains indeed both small nanoparticles $(4 \mathrm{~nm})$ responsible for the linearly adsorbed CO band at $2117 \mathrm{~cm}^{-1}$ and big gold particles $(36 \mathrm{~nm})$ responsible for the low-frequency bands at 2026 and $2002 \mathrm{~cm}^{-1}$ due to bridged $\mathrm{CO}$ adsorbed on large particles. Therefore, the difference in the spectra of the two monometallic gold samples reflects the different dispersion of the two samples, being higher in the catalyst obtained with the 5-day-aged solution. As shown in Fig. 8, all the IR signals are completely removed by the evacuation, confirming the reversible character of CO adsorption on gold over silica [41].

Fig. 9 displays the FT-IR spectra of the monometallic Pt-containing catalysts detected in the presence of 50 Torr of $\mathrm{CO}$ (thick line) and after the evacuation for $30 \mathrm{~min}$ at room temperature (thin line). As shown in Fig. 9a, the spectrum of the Pt0 sample, when exposed to $\mathrm{CO}$, contains a strong band at $2090 \mathrm{~cm}^{-1}$ and weaker bands at $2035 \mathrm{~cm}^{-1}, 2000 \mathrm{~cm}^{-1}$, and $1850 \mathrm{~cm}^{-1}$. The band at $2090 \mathrm{~cm}^{-1}$ is characteristic of CO adsorbed linearly on metallic Pt [43-45], and the broad absorption at $1850 \mathrm{~cm}^{-1}$ is due to $\mathrm{CO}$ adsorbed on bridge sites of Pt $[44,45]$. The origin of the weak bands at 2035 and $2000 \mathrm{~cm}^{-1}$ is not clear, and they are tentatively assigned to $\mathrm{CO}$ adsorbed in bridging form on positively charged platinum particles $\left(\mathrm{Pt}^{+}\right)$. A closer inspection of the peak at $2090 \mathrm{~cm}^{-1}$ reveals an asymmetric tailing in the high-frequency region which can be due to $\mathrm{CO}$ adsorbed linearly on positively charged platinum. The CO evacuation causes the disappearance of the absorptions at 2035 and $2000 \mathrm{~cm}^{-1}$ and an increase in the intensity of the $2090 \mathrm{~cm}^{-1}$ band which is shifted to $2084 \mathrm{~cm}^{-1}$. It can be proposed that during the removal of $\mathrm{CO}$, a transformation of the bridged carbonyls coordinated to the $\mathrm{Pt}^{+}$sites to linearly $\mathrm{Pt}^{+}-\mathrm{CO}$ species takes place resulting in enhancement of the adsorption at $2084 \mathrm{~cm}^{-1}$. The bridged carbonyls at $1850 \mathrm{~cm}^{-1}$ are stable upon evacuation. The obvious discrepancy between the FT-IR detection of metallic platinum and the absence of metallic Pt component in the Pt $4 \mathrm{f}$ photoelectron spectra can be explained with the reduction in platinum occurred during the activation of the samples under vacuum at $350^{\circ} \mathrm{C}$ prior the FT-IR measurements. Such possibility was indeed verified by performing XPS analyses of the samples pretreated in situ under vacuum and at $350^{\circ} \mathrm{C}$.

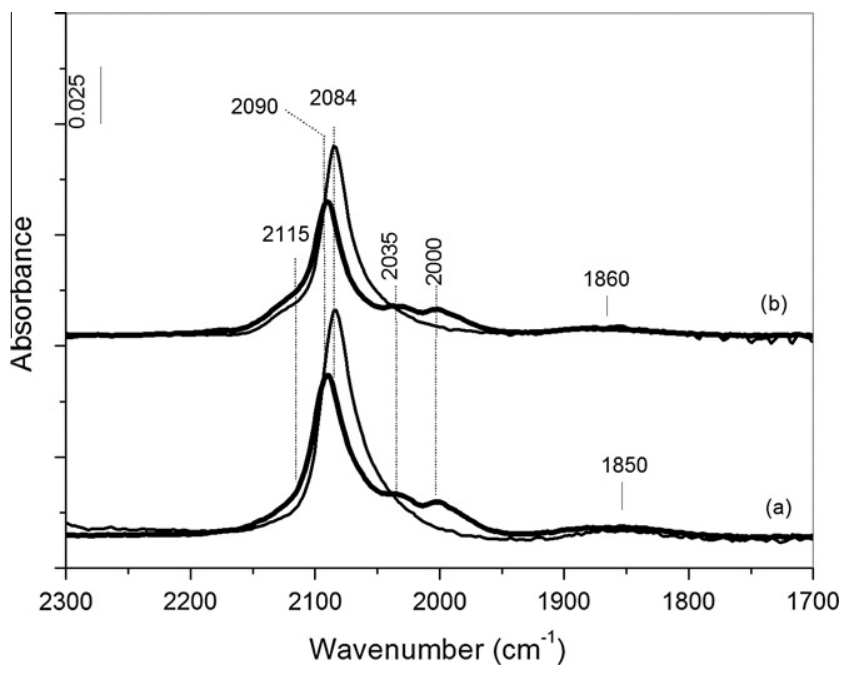

Fig. 9. FTIR spectra of $\mathrm{CO}$ ( 50 Torr) adsorbed at room temperature (thick line) and after evacuation of $\mathrm{CO}$ for $30 \mathrm{~min}$ at room temperature (thin line) on (a) Pt0 and (b) Pt5 
The assignment of the bands detected upon adsorption of $\mathrm{CO}$ on the Pt5 (Fig. 9b) is analogous to that for the Pt0 sample but with some differences: (i) a clear shoulder at $2115 \mathrm{~cm}^{1}$ in the spectrum of the former catalyst is assigned to CO adsorbed on PtO [46,47], and (ii) the intensities of the bands at 2090, 2035, and $2000 \mathrm{~cm}^{-1}$ are lower than those of the Pt0_400 sample in accord with the differences of the XPS-derived atomic ratios. Also, in this case, the evacuation causes the increase in the intensity of the band at $2090 \mathrm{~cm}^{-1}$ (shifted to $2084 \mathrm{~cm}^{-1}$ ) and the disappearance of two bands at 2035 and $2000 \mathrm{~cm}^{-1}$. There is no substantial change in the intensity of the shoulder at $2115 \mathrm{~cm}^{-1}$, which confirms the assignment of this feature to $\mathrm{CO}$ adsorbed on PtO.

The adsorption of $\mathrm{CO}$ on the bimetallic catalysts is shown in Fig. 10 for the three bimetallic samples obtained with the different aged solutions. The spectrum of the AuPt0 sample (Fig. 10a) has a band at $2126 \mathrm{~cm}^{-1}$, which can be assigned to CO adsorbed on positively charged gold particles $\left(\mathrm{Au}^{+}\right)$[34-37]. The presence of this band, which was not detected during the $\mathrm{CO}$ adsorption on the monometallic Au0 catalyst, according to literature, is due to formation of bimetallic AuPt particles [45,48-52]. The band with maximum at $2090 \mathrm{~cm}^{-1}$ is rather complex with shoulders at 2060 , 2034 , and $2000 \mathrm{~cm}^{-1}$. Upon evacuation, the unresolved signals at 2034 and $2000 \mathrm{~cm}^{-1}$ disappear. The shoulder at $2060 \mathrm{~cm}^{-1}$ persists and can be assigned to CO adsorbed on Pt sites, which are incorporated into gold particles [48-50,52]. The absorption at $2090 \mathrm{~cm}^{-1}$ and the signals at 2034 and $2000 \mathrm{~cm}^{-1}$ observed in CO atmosphere indicate the coexistence of monometallic Pt sites together with bimetallic particles giving rise to the large $\mathrm{Pt}^{0}-\mathrm{CO}$ band at $\sim 2060 \mathrm{~cm}^{-1}$. The dilution of Pt atoms in Au leads to physical separation of the Pt-CO dipoles resulting in reduced dipole coupling and consequent red-shift $\left(\sim 30 \mathrm{~cm}^{-1}\right)$ of the $\mathrm{Pt}^{0}-\mathrm{CO}$ band relative to that on the pure Pt0_400 catalyst [48]. Mihut et al. [49], based on the adsorption of ${ }^{12} \mathrm{CO} /{ }^{13} \mathrm{CO}$ mixture on cluster-derived AuPt bimetallic catalysts, concluded that the red-shift is caused by electronic effect due to enhanced -back donation to the adsorbed $\mathrm{CO}$ molecule. Mott et al. [51] proposed that the electronic effect causing the red-shift is associated with the d-band shift of Pt in the bimetallic particles. As for the monometallic platinum samples, the absorption at $2115 \mathrm{~cm}^{-1}$ is attributed to $\mathrm{CO}$ adsorbed on PtO.

The spectrum of the AuPt1_400 sample, shown in Fig. 10b, is similar to the AuPt0 catalyst. Dilution of Pt in Au is supported by the presence of shoulder at $\sim 2060 \mathrm{~cm}^{-1}$ due to CO adsorbed on

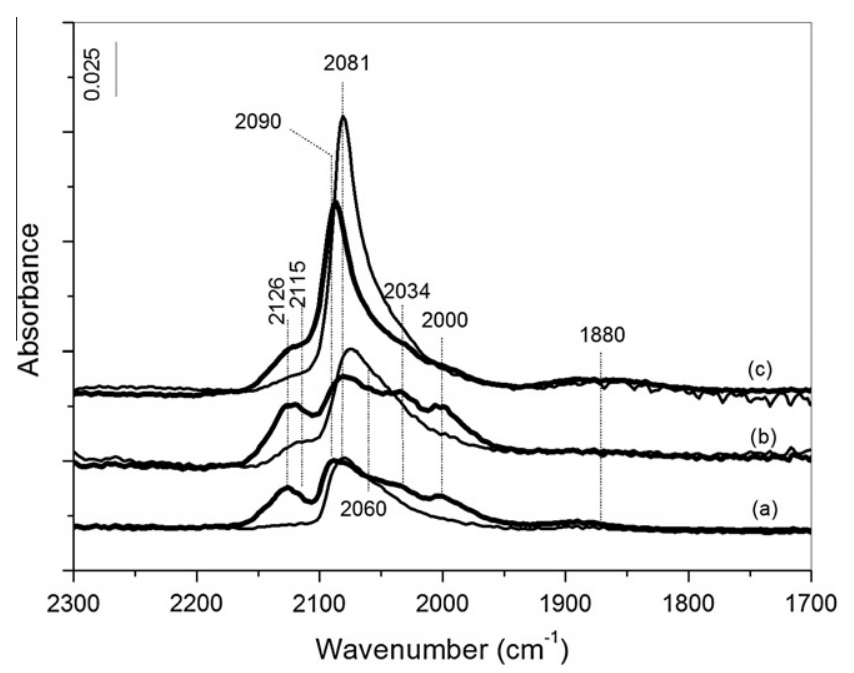

Fig. 10. FTIR spectra of $C O$ ( 50 Torr) adsorbed at room temperature (thick line) and after evacuation of $\mathrm{CO}$ for $30 \mathrm{~min}$ at room temperature (thin line) on (a) AuPt0, (b) AuPt1 and (c) AuPt5.
$\mathrm{Pt}^{0}$ in the bimetallic phase $[48,49,52]$. As discussed for the previous sample, the monometallic Pt phase characterized by CO bands at $2090 \mathrm{~cm}^{-1}$ (Pt-CO) and 2034 and $2000 \mathrm{~cm}^{-1}$ coexists with the bimetallic Au-Pt phase.

Quite interesting, the spectrum produced during the adsorption of $\mathrm{CO}$ on the AuPt5 catalyst (Fig. 10c) is quite similar to that of the monometallic Pt5 sample (Fig. 9b) although the overall absorption is characterized by higher intensity. The dilution of $\mathrm{Au}$ atoms in $\mathrm{Pt}$ would result in the formation of smaller Pt particles giving rise to more intense platinum carbonyl bands because of the increased number of CO coordination sites. The same behavior of the monometallic is also obtained after the evacuation of the CO.

It is worth noting that the overall intensities of the platinum-related $\mathrm{CO}$ absorption bands in the spectra of AuPt0, AuPt 1 , and AuPt5 catalysts increase with the aging time of the solution of metal precursors with the 3-mercaptopropyltriethoxysilane (3MPTES) indicating an increase in the platinum dispersion in accord with the XPS results.

\section{Discussion}

The above described characterization results along with the catalytic tests point out to a direct control of the bimetallic AuPt particles in terms of structural and chemical composition. The use of the ligand MPTES, both as stabilizing agent and as carrier for the metal particle deposition over silica, drives the formation of different structures in virtue of the different affinity of gold and platinum versus sulfur $\left(\Delta H_{\mathrm{Pt}-\mathrm{S}}=56.27 \mathrm{kcal} / \mathrm{mol}\right.$ [53]; $\Delta H_{\mathrm{Au}-\mathrm{S}}=$ $34 \mathrm{kcal} / \mathrm{mol}$ [54]). In the monometallic samples, the aging time allows a better dispersion of the gold particles due to the increasing interaction between gold and sulfur. In the presence of the silica support, the hydrolysis and condensation of the alcoholic function of the MPTES linked to the metal particles determine the subsequent anchoring of the gold to the silica surface, leading to the formation of smaller particles. Since the interaction of platinum with sulfur is stronger than the interaction of sulfur with gold, the dispersion of the monometallic platinum catalysts is overall higher than the corresponding monometallic gold samples. At time 0 , the strong interaction between Pt and S led to the dispersion of all the platinum with the consequent formation of particles ought to be smaller than $2 \mathrm{~nm}$ in accord with the absence of any platinum-related XRD peaks. According to the decreasing XPS-derived $\mathrm{Pt} / \mathrm{Si}$ atomic ratio, the aging time of the precursor solution led to an apparent decrease of the platinum dispersion. However, the absence of XRD reflections and the simultaneous decrease in the $\mathrm{S} / \mathrm{Si}$ atomic ratio observed in the dried samples suggests lower XPS accessibility of the species in the Pt5 as compared to Pt0, rather than an actual enlargement of the Pt particles. Indeed, the MPTES may rearrange itself with time before grafting to the silica surface, embedding the Pt-S entity. This possibility is corroborated also by the similar HDS activities shown by the Pt0 and the Pt5 samples.

The explanation for the bimetallic behavior is more complicated; in this case, the relative strength of the bonds Au-S, Pt-S, and $\mathrm{Au}-\mathrm{Pt}$ and the metal reducibility play a fundamental role in the electronic and morphological properties of the final particles. According to XRD analyses, at time zero and in the calcined samples, large platinum particles of $13 \mathrm{~nm}$ are formed along with smaller $(3 \mathrm{~nm})$ gold enriched alloyed particles. Such result, which may appear in contrast with the monometallic sample behavior, is associated with the rapid formation of the Pt-S interaction and also with a rapid reduction in the gold precursor to metallic $\mathrm{Au}$ in the alcoholic solution. Upon addition of silica, the platinumMPTES complex is rapidly incorporated into the silica surface by the condensation process, whereas the gold will deposit over the 

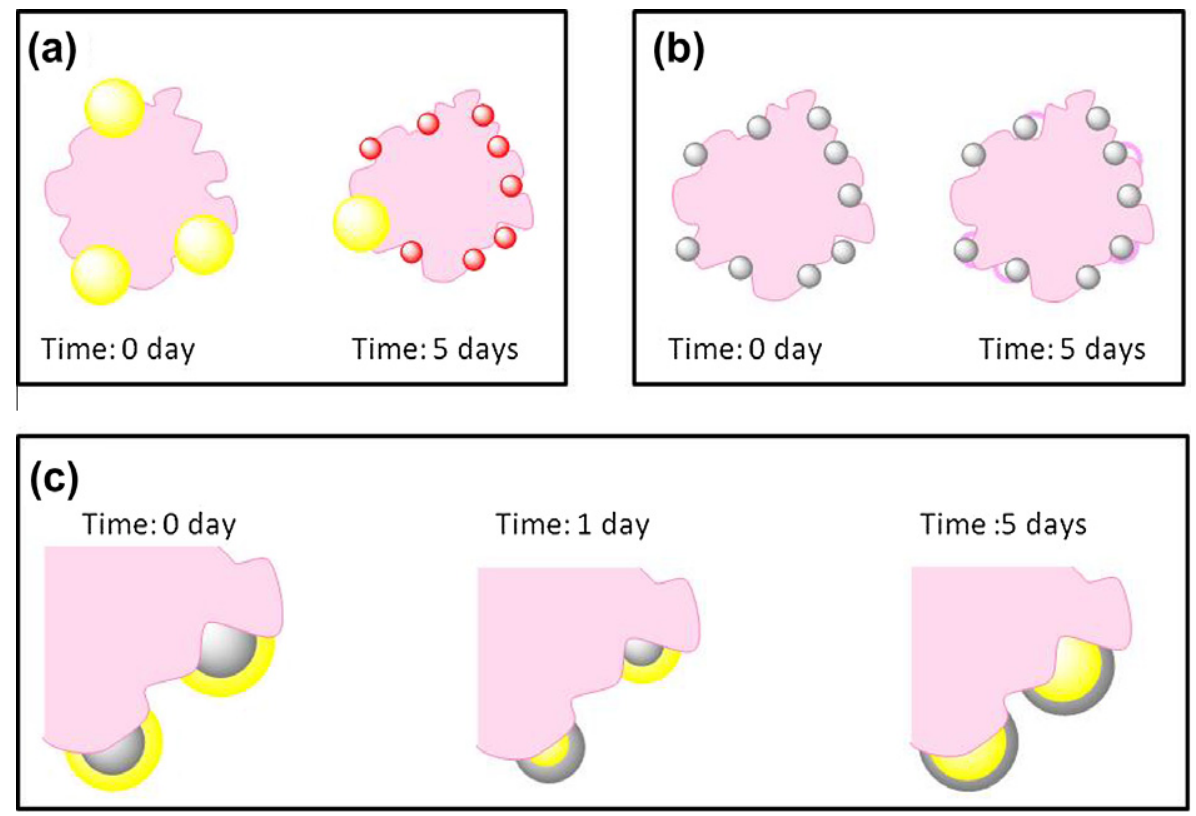

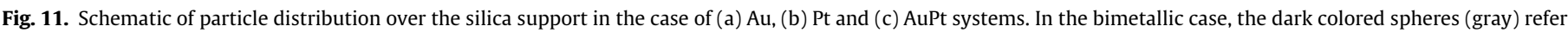

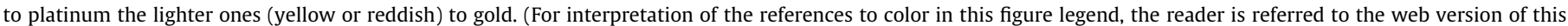
article.)

platinum. After calcinations and removal of sulfur, the interaction between the metallic gold and the anchored platinum would prevail over the interaction between gold and silica, inducing the reduction of platinum with formation of a stable AuPt structure $[55,56]$. A core-shell structure with the inner core made of platinum and an external layer of thin but still XRD detectable AuPt alloyed phase is formed. Such structural configuration would be in accord with the large Au/Pt XPS-derived atomic ratio, the low HDS activity and the FTIR peaks of CO adsorbed on bimetallic particles. By letting the solution rest for 1 day before adding silica, the extent of the interaction Au-S affects the final structure of the calcined samples producing small particles of metallic gold and metallic platinum, as shown by the XRD, possibly covered by a thinner shell of AuPt alloy as suggested by the FTIR CO absorption experiments. The further extension of the aging time causes the inversion of the time zero situation, with formation of a large core of gold, with a shell of a thin layer of alloy. In this case, the long reaction time between the metal precursors and the MPTES would favor capping of both metal ions. Upon addition of the support, the silica condensation with the MPTES carrying the metal ions would produce a good dispersion of both metals. During calcination, the gold strongly anchored to the silica surface would form a reverse core-shell structure with respect to that predicted by theoretical and experimental investigation [56,57]. In accord with the XPS $\mathrm{Au} / \mathrm{Pt}$ atomic ratio and with the $\mathrm{CO}$ adsorption FTIR results, a structural change from a $\mathrm{Pt}_{\mathrm{core}}-\mathrm{AuPt}_{\text {shell }}$ like structure to a $\mathrm{Au}_{\mathrm{core}^{-}}$ $\mathrm{AuPt}_{\text {shell }}$ like structure is taking place by simply extending the time the two metal ions spend in solution with the MPTES ligand. The increased surface exposure of platinum accounts for the increase in the HDS activity. The additional XRD and XPS data on the aged samples confirm the superior structural stability of the AuPt5 as compared to the AuPt0 catalyst. Moreover, the lowest value of the deactivation percentage, obtained with the bimetallic AuPt5, even lower than the value of the monometallic Pt5, proves the beneficial effect of the bimetallic system in inhibiting possible deactivation processes caused by coke or sulfur poisoning [11].

In summary, as obvious from Fig. 2, the adopted method of the MPTES capping is able to yield a much more active monometallic platinum catalyst, as compared to the conventional deposition- precipitation method, regardless the aging time of the Pt precursor solution. In the case of the bimetallic catalyst, the new method produces an active catalyst when sufficiently long aging time of the AuPt precursor solution is allowed. In Fig. 11a schematic representation of the structural differences of the mono- and bi-metallic systems obtained with different aged solution is pictured.

\section{Conclusion}

The MPTES-aided synthesis of Pt, Au, and Au-Pt catalysts supported on commercial $\mathrm{SiO}_{2}$ enabled us to get insights into the structural modification of the AuPt system and possible effects relative to the catalytic behavior in the thiophene hydrodesulfurization reaction. As compared to the conventional DP method, the new approach afforded more active platinum catalysts. The beneficial effect of the particular synthesis is ascribable to the enhanced metal dispersion caused by the interaction of the platinum precursor with the mercapto groups subsequently condensed over the silica surface.

The new procedure applied to the synthesis of the bimetallic AuPt catalysts allows to obtain catalytically active system when the precursor solution is aged for a long time before coming into contact with the silica support. The enhanced activity is related to the structural change of the bimetallic particles, starting with a core-shell configuration with the platinum core, in the case of a short contact time between the metal ions and the MPTES ligand, ending with a core-shell configuration with the gold core, in the case of a long contact time.

The relevance of the synthesis here described resides in the possibility of tuning the reactivity of a bimetallic nanostructured catalysts, by enabling the attainment of a desired core-shell structure which is the reverse of the one predicted on the basis of the bulk properties.

\section{Acknowledgments}

Support by the NATO Grant ESP.CLG. No.984160 and COST action CM0903 is kindly acknowledged. 


\section{References}

[1] Y. Kanda, T. Kobayashi, Y. Uemichi, S. Namba, M. Sugioka, Appl. Catal. A: Gen. 308 (2006) 111-118.

[2] D. Trong On, D. Desplantier-Giscard, C. Danumah, S. Kaliaguine, Appl. Catal. A 253 (2003) 545-602.

[3] A. Corma, A. Martinez, V. Martinez-Soria, J. Catal. 169 (1997) 480-489.

[4] H. Topsøe, B.S. Clausen, F.E. Massoth, in: J.R. Anderson, M. Boudart (Eds.), Hydrotreating Catalysis, Springer-Verlag, Berlin, 1996.

[5] B.H. Cooper, B.B.L. Donnis, Appl. Catal. A: Gen. 137 (1996) 203-223.

[6] J. Barbier, E. Lamy-Pitara, P. Marecot, J.P. Boitiaux, J. Cosyns, F. Verna, Adv. Catal. 37 (1990) 279-318.

[7] J.C. Rodríguez, J. Santamaría, A. Monzón, Appl. Catal. A: Gen. 165 (1997) 147157.

[8] C. Song, ChemTech 29 (1999) 26-30.

[9] A.M. Venezia, R. Murania, V. La Parola, B. Pawelec, J.L.G. Fierro, Appl. Catal. 383 (2010) 211-216.

[10] M.M. Hossain, Chem. Eng. J. 123 (2006) 15-23.

[11] A.M. Venezia, V. La Parola, V. Nicolì, G. Deganello, J. Catal. 212 (2002) 56-62.

[12] B. Pawelec, A.M. Venezia, V. la Parola, S. Thomas, J.L.G. Fierro, Appl. Catal. A 283 (2005) 165-167.

[13] G. Deganello, D. Duca, L.F. Liotta, A. Martorana, A.M. Venezia, A. Benedetti, G. Fagherazzi, J. Catal. 151 (1995) 125-134.

[14] G.C. Bond, D.T. Thompson, Catal. Rev. Sci. Eng. 41 (3\&4) (1999) 319.

[15] A. Corma, P. Serna, Science 313 (2006) 332.

[16] A.M. Venezia, V. La Parola, G. Deganello, B. Pawelec, J.L.G. Fierro, J. Catal. 215 (2003) 317-325.

[17] P. Serna, P. Conceptiòn, Avelino Corma, J. Catal. 265 (2009) 19-25.

[18] B. Pawelec, A.M. Venezia, V. la Parola, E. Cano-Serrano, J.M. Campos-Martin, J.L.G. Fierro, Appl. Surf. Sci. 242 (2005) 380-391.

[19] V. La Parola, M.L. Testa, A.M. Venezia, Appl. Catal. B 119-120 (2012) 248-255.

[20] V. Ponec, G.C. Bond, Catalysis by Metals and Alloys, Studies in Surface Science and Catalysis, vol. 95, Elsevier, Amsterdam, 1995.

[21] G.C. Bond, Platinum Metal Rev. 51 (2007) 64-68.

[22] JCPDS Powder Diffraction File Int. Centre for Diffraction Data, Swarthmore, 1989; File No. 42-1467.

[23] D.A. Shirley, Phys. Rev. B 5 (1972) 4709-4714.

[24] P.M.A. Sherwood, in: D. Briggs, M.P. Seah (Eds.), Practical Surface Analysis, Wiley, New York, 1990, p. 181.

[25] A.R. West, Solid State Chemistry and its Applications, Wiley, Chichester, UK, 1998.

[26] C. Gentilini, F. Evangelista, P. Rudolf, P. Franchi, M. Lucarini, L. Pasquato, J. Am. Chem. Soc. 130 (2008) 15678-15682.

[27] M.L. Testa, V. La Parola, A.M. Venezia, Catal. Today 158 (2010) 109-113.

[28] H.I. Lee, S.H. Joo, J.H. Kim, D.J. You, J.M. Kim, J.N. Park, H. Chang, C. Pak, J. Mater. Chem. 19 (2009) 5857-6052.

[29] Z. Wu, Z. Sheng, Y. Liu, H. Wang, J. Mol. J. Hazard. Mater. 185 (2011) 10531058.

[30] L.K. Ono, B. Yuan, H. Heinrich, B. Roldan Cuenya, J. Phys. Chem. C 114 (2010) 22119-22133.
[31] X. Li, J. Liu, W. He, Q. Huang, H. Yang, J. Colloid Interface Sci. 344 (2010) 132 136.

[32] Y. Xu, Y. Dong, J. Shi, M. Xu, Z. Zhang, X. Yang, Catal. Commun. 13 (2011) 54 58.

[33] R.P. Doherty, J.M. Krafft, C. Methivier, S. Casale, H. Remita, C. Louis, C. Thomas, J. Catal. 287 (2012) 102-113.

[34] F. Boccuzzi, G. Cerrato, F. Pinna, G. Strukul, J. Phys. Chem. B 102 (1998) 5733 5736

[35] M. Maciejewski, P. Fabrizioli, J.-D. Grunwald, O.S. Becker, A. Baiker, Phys. Chem. Chem. Phys. 3 (2001) 3846-3855

[36] T. Tabakova, F. Boccuzzi, M. Manzoli, J.W. Sobczak, V. Idakiev, D. Andreeva, Appl. Catal. A 298 (2006) 127-143.

[37] M. Kantcheva, O. Samarskaya, L. Ilieva, G. Pantaleo, A.M. Venezia, D. Andreeva, Appl. Catal. B 88 (2009) 113-126.

[38] F. Boccuzzi, A. Chiorino, M. Manzoli, D. Andreeva, T. Tabakova, J. Catal. 188 (1999) 176-185.

[39] D. Andreeva, M. Kantcheva, I. Ivanov, L. Ilieva, J.W. Sobczak, W. Lisowski, Catal. Today 158 (2010) 69-77.

[40] K. Chakarova, M. Mihaylov, S. Ivanova, M.A. Centeno, K. Hadjiivanov, J. Phys Chem. C 115 (2011) 21273-21282.

[41] J.Y. Lee, J. Schwank, J. Catal. 102 (1986) 207-215.

[42] F. Somodi, I. Borbàth, M. Hegedus, A. Tompos, I.E. Sajò, A. Szegedi, S. Rojas, J.L.G. Fierro, J.L. Margitfalvi, Appl. Catal. A: Gen. 347 (2008) 216-222.

[43] M.J. Kappers, J.H. van der Maas, Catal. Lett. 10 (1991) 365-374.

[44] S.J. Podkolzin, J. Shen, J.J. de Pablo, J.A. Dumesic, J. Phys. Chem. B 104 (2000) 4169-4180.

[45] J. Shen, M. Hill, R.M. Watwe, S.G. Podkolzin, J.A. Dumesic, Catal. Lett. 60 (1999) $1-9$

[46] K.I. Hadjiivanov, G.N. Vayssilov, Adv. Catal. 47 (2002) 307-511.

[47] M.G. Falco, J.M. Grau, N.S. Fígoli, Appl. Catal. A 264 (2004) 183-192.

[48] H. Lang, S. Maldonado, K.J. Stevens, B.D. Chandler, J. Am. Chem. Soc. 126 (2004) 12949-12956

49] C. Mihut, C. Descorme, D. Duprez, M.D. Amiridis, J. Catal. 212 (2002) 125-135.

[50] B.D. Chandler, L.I. Rubinstein, L.H. Pignolet, J. Mol. Catal. A 133 (1998) 267282.

[51] D. Mott, J. Luo, P.N. Njoki, Y. Lin, L. Wang, C. Zhong, Catal. Today 122 (2007) 378-385.

[52] B.D. Chandler, A.B. Schabel, C.F. Blanford, L.H. Pignolet, Catal. Today 187 (1999) 367-384.

[53] H. Toulhoat, P. Raybaud, S. Kaszeelan, G. Kresse, J. Hafner, Catal. Today 50 (1999) 629-636.

[54] C.S.S.R. Kumar, M. Aghasyan, H. Modrow, E. Doomes, C. Henk, J. Hornes, J Nanopart. Res. 6 (2004) 369-376.

[55] L. Leppert, S. Kümmel, J. Phys. Chem. C 115 (2011) 6694-6702.

[56] F. Wang, P. Liu, D. Zhang, J. Mol. Model. 17 (2011) 1069-1073.

[57] B.N. Wanjala, J. Luo, R. Loukrakpam, B. Fang, D. Mott, P.N. Njoki, M. Engelhard, H.R. Naslund, J.K. Wu, L. Wang, O. Malis, C.-J. Zhong, Chem. Mater. 22 (2010) 4282-4294. 